\title{
An Immunohistochemical Study on Renal Biopsies in Children
}

\author{
NORBORU KOBAYASHI* \\ From the Department of Morbid Anatomy, The Hospital for Sick Children, Great Ormond Street, London W.C.1
}

It is over 120 years since Richard Bright first described the condition of nephritis, a symptom complex of oedema, haematuria, and proteinuria, following scarlatina. Since then various investigators have suggested that nephritis and the nephrotic syndrome may be immunologically determined. The possibility of 'hypersensitivity' as the pathogenic mechanism was suggested by Schick (1907) and the experimental production of heteroimmune nephritis by Masugi (1934). At present the evidence for the immunopathogenesis of nephritis and the nephrotic syndrome can be summarized as follows.

(i) Antecedent infection, especially by $\beta$-haemolytic streptococci Group A, type 12, or others, and the latent period before the onset of glomerulonephritis.

(ii) Decrease in the serum complement level during the active phase of glomerulonephritis and the nephrotic syndrome (McCrory, 1960).

(iii) Demonstration of circulating anti-kidney antibody in the serum in these diseases (Lange, Gold, Weiner, and Simon, 1949; Liu and McCrory, 1958).

(iv) Immunohistochemical demonstration of $\gamma$-globulin and complement bound to the glomeruli in these diseases.

(v) Various renal disorders associated with conditions such as the Schönlein-Henoch syndrome, polyarteritis nodosa, systemic lupus erythematosus, rheumatoid arthritis, and serum sickness.

(vi) Experimental production of these diseases by immunological methods.

Among this evidence, the immunohistochemical demonstration of glomerular-bound globulin appears to be of practical and theoretical importance. This was first shown in human tissue by Mellors and Ortega (1956), by means of Coons' fluorescent antibody method. Since then the same method has been applied to various types of renal disease, and

\footnotetext{
Received March 24, 1966.

$\star$ Present address : Department of Pediatrics, Faculty of Medicine, University of Tokyo, Tokyo, Japan.
}

the glomerular-bound globulin has been demonstrated in acute diffuse glomerulonephritis, chronic membranous glomerulonephritis, nephritis complicating periarteritis nodosa, renal amyloidosis, lupus nephritis, pure nephrosis, and glomerulonephritis associated with the nephrotic syndrome (Mellors, Ortega, and Holman, 1957; Vazquez and Dixon, 1957; Taft, Dineen, and McKay, 1958; Freedman, Peters, and Kark, 1960; McKay and Taft, 1961; Burkholder, 1961; Lachmann, Müller-Eberhard, Kunkel, and Paronetto, 1962; Seegal, 1962).

At The Hospital for Sick Children, Great Ormond Street, renal biopsy has been a routine diagnostic method since 1958; much of the biopsied tissue has been subjected to immunohistochemical, enzymehistochemical, and electron microscopic study since 1962 , in addition to routine histopathological study. The results of some of these investigations are reported elsewhere (Bodian, Black, Kobayashi, Lake, and Shuler, 1965; Black and White, 1965).

The purpose of this paper is to summarize the results of the immunohistochemical studies only, and to correlate the presence of the glomerularbound globulin with the clinical manifestations at the time of biopsy. The significance of the glomerular-bound globulin is discussed, and present concepts of the immunopathogenesis of glomerulonephritis and the nephrotic syndrome are summarized.

\section{Material and Methods}

There were available 116 renal biopsies, needle and wedge, at The Hospital for Sick Children or referred there from elsewhere. In addition, renal tissue from 15 post-mortem cases and from 3 nephrectomy cases were studied. Out of this number, 33 needle biopsy cases were unsuitable as the tissue did not contain any glomeruli, leaving 101 preparations (98 cases) for evaluation.

These have been classified into 8 groups on a clinicopathological basis. The definition of the groups and the number of the cases in each are shown in Table $I$.

Renal biopsy was carried out percutaneously by needle or by open operation. The details of the method are 
TABLE I

Definition and Number of Cases in Groups

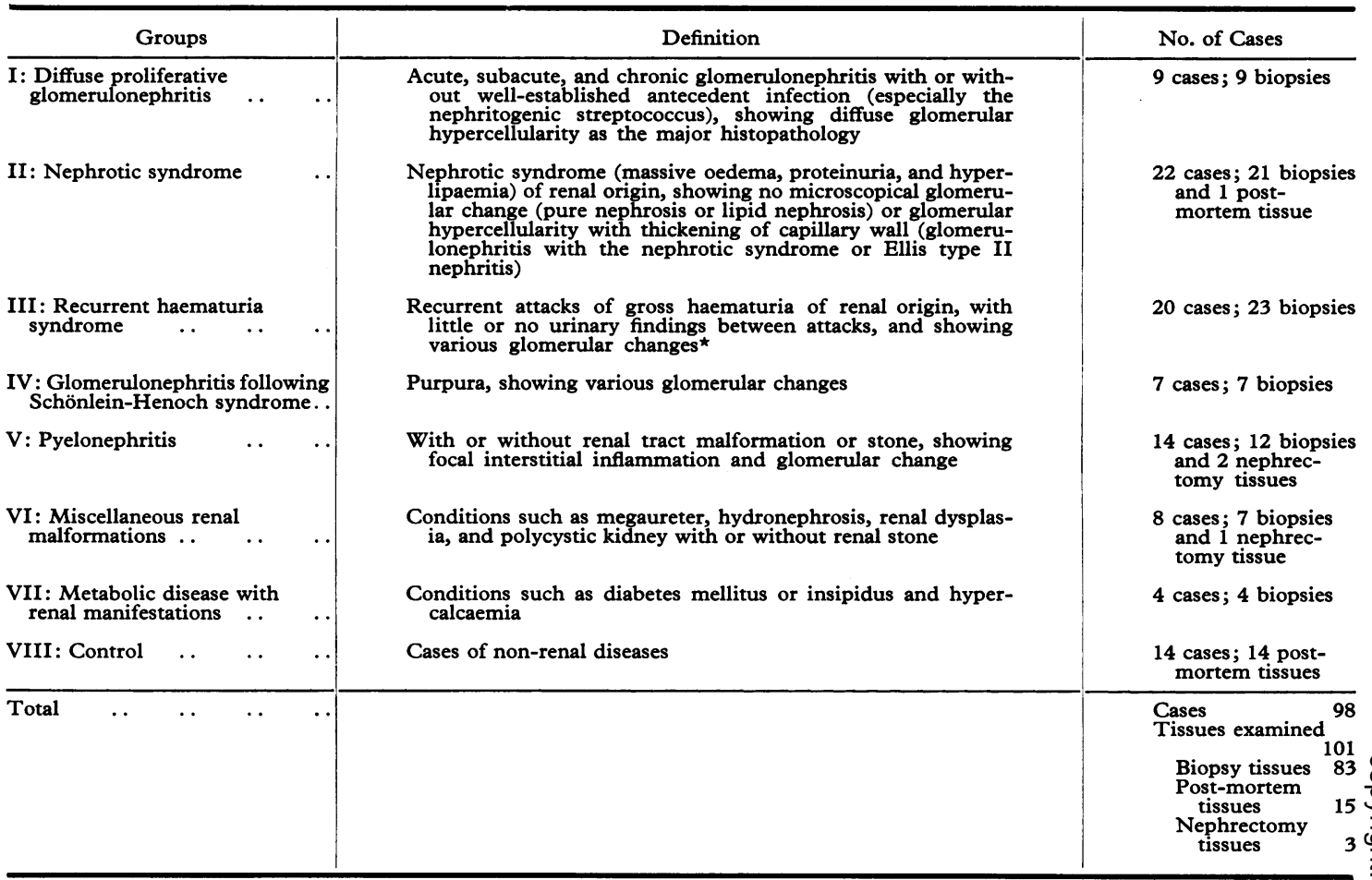

* In order to describe details of the glomerular pathology in Group III, the following terminology is used. Focal, affecting only some glomeruli; generalized, affecting all glomeruli; segmental, affecting one or more areas or tufts within each involved glomerulus; diffuse, affecting whole areas or all tufts within each involved glomeruli.

The term 'diffuse', which is used in the other groups, is 'generalized diffuse' by this terminology, unless specifically mentioned.

described in previous publications (Bodian et al., 1965; Black and White, 1965).

The tissue was divided into three portions, two of which were subjected to routine histology and electronmicroscopy. The third portion was quick-frozen in a piece of animal liver with solid carbon dioxide, for immunohistochemical and enzyme-histochemical studies.

For immunohistochemical study the Coons' fluorescent antibody method (Coons, 1956, 1958; Beutner, 1961; Nairn, 1962) was modified as follows. Sections were cut on a cryostat at 5-7 $\mu$ thickness and placed on thin slides; air-dried at room temperature for $5 \mathrm{~min}$.; covered completely with a few drops of fluorochromed antisera; placed in a moist chamber and incubated at $37^{\circ} \mathrm{C}$. for $30 \mathrm{~min}$.; washed once in saline-phosphate buffer $(p \mathrm{H} \mathrm{7 \cdot 2)}$ and then placed in a fresh bath of the solution, which was agitated gently and continuously by a magnetic stirrer for $10 \mathrm{~min}$.; and finally, mounted in Difco's buffered fluorescence-free medium and examined under an ultraviolet light source.

For this procedure, the antisera used were as follows.

(1) Anti-human globulins (Lister Institute, London: Difco Laboratory, U.S.A., Wellcome Laboratory \& Co.,
London; Stayne Laboratory Ltd., Bucks.): react with all immunoglobulin.

(2) Anti-human total $\gamma$-globulin (Immunology Inc., U.S.A.): reacts with $\gamma \mathrm{G}$ and $\gamma \mathrm{M}$.

(3) Anti-human 7S $\gamma$-globulin (Immunology Inc.): specific for $\gamma \mathrm{G}$ with slight cross-reaction with $\gamma \mathrm{M}$.

(4) Anti-human 19S $\gamma$-globulin (Immunology Inc.): specific for $\gamma \mathrm{M}$ by absorption with human $7 \mathrm{~S} \gamma$-globulin.

(5) Anti-human complement $C_{1}$ (proesterase) (Immunology Inc.): stated to be specific Complement $C_{1}^{\prime}$.

(6) Anti-streptococcal Group A (Difco Laboratory, U.S.A.): specific for streptococcus Group A.

All the antisera were conjugated with fluorescein isothiocyanate. The antisera $1,2,3$, and 4 had been checked for purity by the agar precipitin test and the specificity of the antisera 6 had been confirmed by testing with smear of streptococcus Group A.

To determine whether fixation of the tissue was desirable before subjecting it to this immunohistochemical study, a preliminary experiment was carried out on 20 biopsies. It appeared that fixing the sectioned tissue with acetone, alcohol, or formalin made no significant difference to the result; however, the unfixed tissue 


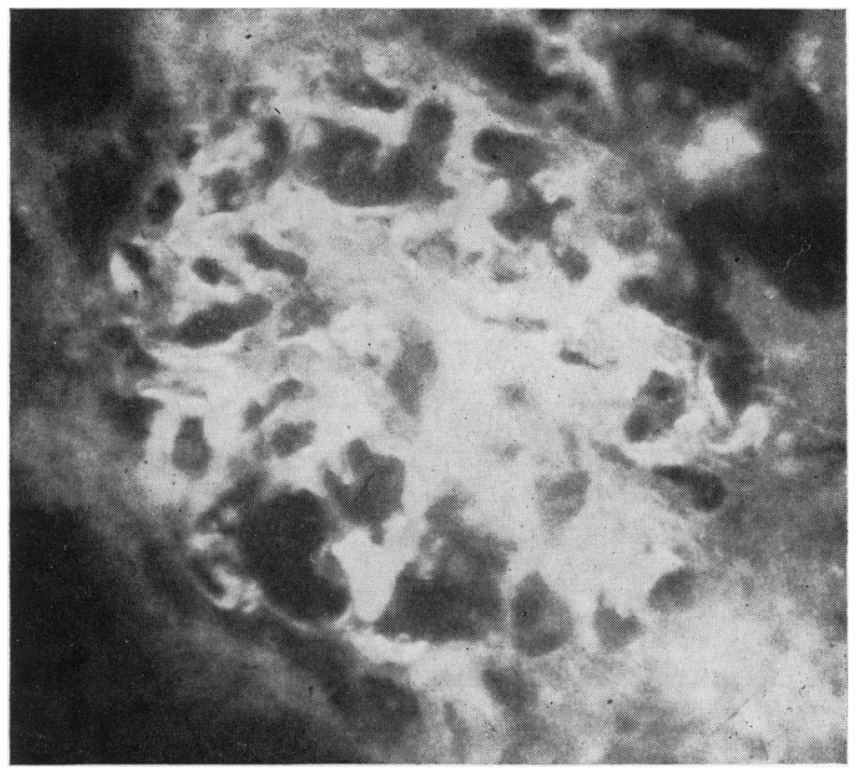

FIG. 1.-Immunohistochemically demonstrated glomerular-bound globulin in renal biopsy from a child aged 3 years 9 months. Clinical diagnosis: nephrotic syndrome. Pathological diagnosis of renal biopsy: pure nephrosis. The biopsy was taken 2 years after the onset of disease, and showed positive fluorescence of apple green colour by the immunohistochemical method. The picture is reproduced from the transparent colour slide. (approximately $\times 400$.)

showed less background fluorescence. Therefore, the test was carried out on unfixed tissue. For the special purpose of demonstrating $\gamma \mathrm{M}$ (19S-), $\gamma \mathrm{G}$ (7S- $\gamma-$ globulin) and complement, both unfixed and fixed tissues were studied. The procedure followed for fixation was that described by Burkholder (1961); the cryostat sections were placed in a bath of anhydrous acetone for 10 minutes at $4^{\circ} \mathrm{C}$., and then air-dried for 15 minutes. A positive fluorescent result was usually well defined (Fig. 1). A negative result showed a punched-out nonfluorescent glomerulus with a weak or non-specific fluorescent area of tubular tissue around. A doubtful result showed a similar or lesser degree of fluorescence in the glomerulus to that in the surrounding renal tissue. A blocking test was also done; the tissue was treated first with non-fluorochromed rabbit anti-human globulin, washed, and then treated with the fluorochromed antihuman globulin as described above. A positive result was recorded when the previously demonstrated fluorescence disappeared following the blocking treatment.

\section{Results}

The relevance of the major clinical findings to the results is shown in Table II.

Immunohistochemical results and their relation to major clinical and histopathological findings, and time of biopsy after onset of disease.
GROUP I: DIFFUSE PROLIFERATIVE GLOMERULONEPHRITIS ( 9 cases; 9 biopsies). Of the 9 cases, 8 were positive. The only case which showed a negative result was considered clinically to be healed glomerulonephritis. In 4 instances glomerulonephritis developed in a patient with another disease -a patient with congenital heart disease and mental retardation; a patient with hydrocephalus infected by staphylococcus before developing haematuria; a patient with duplex kidney; and a patient with megaureter. Since they showed the same histological and clinical features of diffuse glomerulonephritis and were immunochemically positive, a similar immunopathological process to the other cases of this group was considered to be operating.

Among the major clinical findings, proteinuria, haematuria (microscopic), and raised ESR are apparently associated with a positive result. The relation between a positive result and antecedent infection, especially a streptococcal one, is not well established. However, it is considered that the number of the cases in this group is too small to make a statistical evaluation.

GROUP II: THE NEPHROTIC SYNDROME (22 cases; 21 biopsies and one post-mortem tissue). There was one example of the nephrotic syndrome associated with thrombosis of the inferior vena cava, and 
Results of Immunohistochemical Study and Major

\begin{tabular}{|c|c|c|c|c|c|c|c|c|c|c|c|c|}
\hline \multirow{3}{*}{ Group } & \multirow{3}{*}{$\begin{array}{c}\text { Immuno- } \\
\text { histo-- } \\
\text { chemical } \\
\text { Study }^{\star}\end{array}$} & \multicolumn{6}{|c|}{ · } & & & \multicolumn{3}{|c|}{ Maior Clinical andi } \\
\hline & & \multicolumn{2}{|c|}{ Oedema } & \multicolumn{2}{|c|}{$\begin{array}{l}\text { Microscopic } \\
\text { Haematuria }\end{array}$} & \multicolumn{2}{|c|}{ Proteinuria } & \multicolumn{2}{|c|}{ Raised Blood Urea } & \multicolumn{2}{|c|}{$\begin{array}{c}\text { Raised Blood } \\
\text { Pressure }\end{array}$} & $\Phi$ \\
\hline & & + & - & + & - & + & - & + & - & + & - & 暂 \\
\hline $\begin{array}{l}\text { I Glomerulo- } \\
\text { nephritis }\end{array}$ & \pm & $\begin{array}{l}3 \\
0\end{array}$ & $\begin{array}{l}5 \\
1\end{array}$ & $\begin{array}{l}8 \\
0\end{array}$ & $\begin{array}{l}0 \\
1\end{array}$ & $\begin{array}{l}8 \\
0\end{array}$ & $\begin{array}{l}0 \\
1\end{array}$ & $\begin{array}{l}4 \\
0\end{array}$ & $\begin{array}{l}3 \\
1\end{array}$ & $\begin{array}{l}3 \\
0\end{array}$ & $\begin{array}{l}5 \\
1\end{array}$ & 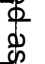 \\
\hline II Nephrosis & \pm & $\begin{array}{r}10 \\
3\end{array}$ & $\begin{array}{l}4 \\
5\end{array}$ & $\begin{array}{l}9 \\
2\end{array}$ & $\begin{array}{l}6 \\
5\end{array}$ & $\begin{array}{r}13 \\
3\end{array}$ & $\begin{array}{l}2 \\
4\end{array}$ & $\begin{array}{l}3 \\
0\end{array}$ & $\begin{array}{r}12 \\
5\end{array}$ & $\begin{array}{l}9 \\
3\end{array}$ & $\begin{array}{l}5 \\
3\end{array}$ & $\$$ \\
\hline $\begin{array}{c}\text { III Recurrent } \\
\text { haematuria }\end{array}$ & \pm & $\begin{array}{r}10 \\
0\end{array}$ & $\begin{array}{l}10 \\
13\end{array}$ & $\begin{array}{l}6 \\
4 \\
\end{array}$ & $\begin{array}{l}4 \\
9 \\
\end{array}$ & $\begin{array}{l}5 \\
3 \\
\end{array}$ & $\begin{array}{r}5 \\
10 \\
\end{array}$ & $\begin{array}{l}1 \\
1\end{array}$ & $\begin{array}{l}7 \\
8 \\
\end{array}$ & $\frac{1}{2}$ & $\begin{array}{r}7 \\
10 \\
\end{array}$ & 屯 \\
\hline $\begin{array}{c}\text { IV Schönlein- } \\
\text { Henoch syndrome }\end{array}$ & \pm & $\begin{array}{l}0 \\
0\end{array}$ & $\begin{array}{l}3 \\
4\end{array}$ & $\begin{array}{l}1 \\
4\end{array}$ & $\begin{array}{l}2 \\
0\end{array}$ & $\begin{array}{l}1 \\
4\end{array}$ & $\begin{array}{l}2 \\
0\end{array}$ & $\frac{1}{2}$ & 2 & $\frac{1}{2}$ & 2 & के \\
\hline A II & \pm & $\begin{array}{r}13 \\
3 \\
\end{array}$ & $\begin{array}{l}22 \\
10\end{array}$ & $\begin{array}{l}24 \\
10\end{array}$ & $\begin{array}{l}12 \\
14 \\
\end{array}$ & $\begin{array}{l}27 \\
10\end{array}$ & $\begin{array}{r}9 \\
14 \\
\end{array}$ & $\begin{array}{l}9 \\
3 \\
\end{array}$ & $\begin{array}{l}24 \\
16 \\
\end{array}$ & $\begin{array}{r}14 \\
7\end{array}$ & $\begin{array}{l}19 \\
16\end{array}$ & \\
\hline$\chi^{2}$ test $\ldots$ & . & & & $0.0{\frac{\chi^{2}}{2}}^{2}$ & $0 \cdot 10$ & $0.01^{x^{2}}$ & $\begin{array}{l}33 \\
0 \cdot 025 \\
\text { it }\end{array}$ & & & & & \\
\hline
\end{tabular}

* + : presence, - : absence, of glomerular-bound globulin.

Remarks: + Sign implies the following:

Oedema: slight to massive.

Microscopical haematuria: more than scanty red cells per high-power field.

Proteinuria: more than trace.

fluorescent examination of the post-mortem renal tissue was here negative. This case may reasonably be excluded from the so-called immunologically determined nephrotic syndrome, leaving 15 positive cases out of 21 .

All 15 cases that were not treated with steroid or ACTH within one month before the biopsy were positive. Even under treatment with steroid or ACTH, 9 out of $15(60 \%)$ were positive. This indicates a fairly high incidence of steroid-resistant cases.

With regard to glomerular pathology, 14 cases showed no change (pure nephrosis), but 7 showed evidence of glomerulonephritis.

Positive fluorescence in Group II was frequent in the first year after the onset of disease $(90 \%)$. All 6 cases of pure nephrosis were positive, as were 3 of the 4 with evidence of glomerulonephritis. In the later stages fluorescence was less frequently demonstrable. A positive result was obtained in 4 out of 8 cases with pure nephrosis and in 2 of the 3 cases of glomerulonephritis.

Proteinuria, raised ESR, oedema, and hypoproteinuria were apparently associated with positive fluorescence.

Congenital nephrotic syndrome. Two were considered clinically to be examples of the congenital nephrotic syndrome, and were subjected to further immunohistochemical study. In one case, however, the renal lesions were found to be due to thrombosis of the inferior vena cava, as stated above. No significant result was obtained by using fluorochromed antisera against human $\gamma$-globulin, $\gamma \mathrm{G}$, $\gamma \mathrm{M}$, and complement $\mathrm{C}_{1}^{\prime}$, and it was considered that no immunological mechanism was operating.

The other case gave a positive result with these antisera, and therefore an immunological mechanism was considered to be operating. Unfortunately this tissue could not be tested against human $\gamma \mathrm{M}$.

One further positive case is worth mentioning since the disease began before the child was 2 years old and was steadily progressive. This may well be similar to infantile nephrosis, which is considered to be a specific entity (Worthen, Vernier, and Good, 1958).

GROUP III: THE RECURRENT HAEMATURIA SYNDROME (20 cases: 23 biopsies). Out of 23 biopsies $(45 \%), 10$ were positive. Within one year of the onset of disease, 4 out of 11 (35\%) were positive and later 6 out of $12(50 \%)$ were positive. The relation between positive result and glomerular pathology is interesting. Of 17 biopsies with purely focal involvement, $6(35 \%)$ were positive, while of those with generalized involvement 4 of $6(65 \%)$ were positive.

The relation between a positive result and frequency of haematuria was not constant. Of the cases which had up to 20 attacks of haematuria before the biopsy, 6 out of 13 (46\%) were positive; of those which had 20 to 50 attacks, 2 out of $3(66 \%)$ were 


\begin{tabular}{|c|c|c|c|c|c|c|c|c|c|c|}
\hline \multirow{2}{*}{\multicolumn{2}{|c|}{ Raised ESR }} & \multicolumn{9}{|c|}{ Others } \\
\hline & & \multicolumn{2}{|c|}{$\begin{array}{l}\text { Association with Streptococ- } \\
\text { cal (or other) Infection }\end{array}$} & \multicolumn{2}{|c|}{ Hypoproteinuria } & \multicolumn{2}{|c|}{ Hypercholesterolaemia } & \multicolumn{3}{|c|}{$\begin{array}{c}\text { Number of Haamaturia Attacks } \\
\text { Before Biopsy }\end{array}$} \\
\hline+ & - & + & - & + & - & + & - & \multirow{3}{*}{ 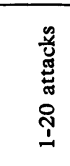 } & \multirow{3}{*}{ 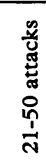 } & \multirow{3}{*}{ 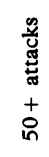 } \\
\hline $\begin{array}{l}5 \\
0\end{array}$ & 1 & $\begin{array}{l}3(3) \\
0\end{array}$ & $\begin{array}{l}2 \\
1\end{array}$ & & & & & & & \\
\hline 9 & $\frac{1}{3}$ & & & $\begin{array}{r}13 \\
3\end{array}$ & $\begin{array}{l}1 \\
3\end{array}$ & $\begin{array}{r}10 \\
3\end{array}$ & $\begin{array}{r}10 \\
1\end{array}$ & & & \\
\hline$\frac{4}{3}$ & $\begin{array}{l}3 \\
8\end{array}$ & $\begin{array}{l}4 \\
3\end{array}$ & $\begin{array}{r}6 \\
10\end{array}$ & & & & & $\begin{array}{l}6 \\
7\end{array}$ & $\begin{array}{l}2 \\
1\end{array}$ & $\begin{array}{l}2 \\
7\end{array}$ \\
\hline$\frac{1}{2}$ & 2 & & & & & & & & & \\
\hline${ }_{8}^{19}$ & $\begin{array}{r}9 \\
12\end{array}$ & & & & & & & & & \\
\hline \multicolumn{2}{|c|}{$\begin{array}{c}x^{2}=2.61 \\
0.05<p<0.10\end{array}$} & & & & & & & & & \\
\hline
\end{tabular}

Raised blood urea; more than $40 \mathrm{mg} . / 100 \mathrm{ml}$

Raised blood pressure; more than 120-100/100-80 mm. $\mathrm{Hg}$, depending on the age of patient.

Raised ESR; more than $10 \mathrm{~mm}$./hr.

Hypoproteinaemia; less than $6 \mathrm{~g} . / 100 \mathrm{ml}$.

Hypercholesterolaemia; more than $220 \mathrm{mg} .100 \mathrm{ml}$.

positive, and of those which had more than 50 attacks, only 2 out of 7 cases ( $28 \%$ ) were positive.

In a given patient with the recurrent haematuria syndrome, no single clinical manifestation is particularly suggestive of an active immunopathological process.

Repeated biopsy study. Among cases in this group, 3 were subjected twice to renal biopsy and immunohistochemical study. In one case, both were negative, though haematuria was noted at least once between biopsies: in this one the glomerular lesion was segmental initially and later became diffuse.

In a second case both were positive, but the second showed an apparently weaker result. Before the second biopsy treatment with steroids was given for 6 months; there was no haematuria between biopsies. Here again, the glomerular involvement became more diffuse.

In a third case, the immunohistochemical study was positive in the first biopsy and negative in the second biopsy. Before the second biopsy, however, frequent attacks of haematuria were noted, and the glomerular involvement became more diffuse.

Recurrent haematuria syndrome in a- $\gamma$-globulinaemia. One case was clinically considered to be a type of a- $\gamma$-globulinaemia: biopsy revealed generalized diffuse glomerulonephritis, and positive fluorescence was obtained. Unfortunately the globulin in glomeruli could not be tested to identify either $\gamma \mathrm{M}$ or $\gamma \mathrm{G}$. This patient was a boy aged 10, who, since the age of 2 years, was noted to have recurrene respiratory infections; and at 4 years he developed collapse of the left lower lobe of the lung, which responded to antibiotics. Five years later the condition recurred and a left lower lobe lobectomy was performed, the diagnosis then being chronic bronchitis with bronchiectasis. Three months later he developed macroscopical haematuria, and since then he has had recurrent attacks of haematuria. Renal biopsy was performed at the age of 10 years, and the diagnosis of generalized diffuse glomerulonephritis was made. The major laboratory findings were as follows: serum protein $4.9 \mathrm{~g} . / 100 \mathrm{ml}$., slight reduction in albumin, relatively normal $\alpha$ - and $\beta$ globulin, complete absence of $\gamma$-globulin. Immunoelectrophoresis, $\gamma \mathrm{M}, 25 \%$ of normal; $\gamma \mathrm{M}$ globulin, $0.4 \%$ of normal; Mantoux test positive; isoagglutinin, anti-B positive; failure of antibody response to polio-immunization.

GROUP IV: NEPHRITIS FOLLOWING SCHÖNLEINHENOCH SYNDROME ( 7 cases: 7 biopsies). Of the 7 cases, 3 were positive. Since the number in this group is small, no further conclusion can be drawn. However, a positive result is apparently more likely within the first year after the onset of disease in cases with the generalized glomerular involvement, and in cases without steroid treatment. 
Group V: PYELONEPHRITIS (14 cases: 12 biopsies and 2 nephrectomy tissues). Of the 14 cases, 3 gave a doubtful result and the remainder were negative.

It is interesting to note that many of the cases showed lymphocytic infiltration and lymphofollicular formation on routine histological examination: considered to be due to chronic and repeated infection. However, since an immunological process cannot be excluded completely on the basis of the immunohistochemical findings, the infiltration may be the morphological manifestation of an immunological process.

Three patients in this group had recurrent attacks of haematuria. 7 were associated with some form of renal tract malformation.

GROUP VI: miscellaneous renal malformations (8 cases: 7 biopsies and one nephrectomy tissue). All 8 cases were negative, as expected from the clinical and pathological diagnosis.

GROUP VII : metabolic diseases with renal manifestations ( 4 cases: 4 biopsies). All 4 cases were negative. (Renal manifestations in these cases were not those of nephritis or of the nephrotic syndrome.)

GrouP VIII: control (14 cases: 14 necropsies). All were negative.

Special study with anti-human $\gamma M$ - and $\gamma$ G-globulin, anti-human complement ( $\mathbf{C}_{1}^{\prime}-$ proesterase) and anti-streptococcal Group $A$ sera. 15 positive cases were subjected to further study in order to determine the nature of the demonstrated $\gamma$-globulin and to demonstrate complement $\left(\mathrm{C}_{1}^{\prime}\right)$. In all cases complement was identified. The demonstrated globulin is, therefore, immunologically significant in these cases. Concerning $\gamma \mathrm{G}$ versus $\gamma \mathrm{M}$, cases from Group I (5 cases) appeared to show more $\gamma \mathrm{M}$, while cases from Group II (4 cases) appear to show more $\gamma \mathrm{G}$. However, the number in each group was too limited to draw any conclusion.

Tissues from 33 cases ( 5 in Group I; 9 in Group II; 8 in Group III; 3 in Group IV; 6 in Group V; 1 in Group VI, and 1 in Group VIII) were exposed to anti-streptococcal Group A antisera, but the results were negative.

Haematuria and proteinuria in immunologically determined nephropathy. The relation between haematuria and proteinuria and presence of glomerular-bound globulin in Groups I, II, III, and IV was examined statistically. The presence of glomerular-bound globulin is statistically associated with proteinuria $\left(\chi^{2}=5 \cdot 43\right.$, $0.01<\mathrm{p}<0.025)$, but not with haematuria $\left(\chi^{2}=2 \cdot 72,0.05<\mathrm{p}<0 \cdot 19\right)$.

\section{Genetic consideration and immunohisto- chemical study.}

FAMILIAL FACTOR. In this series 4 cases were familial. (a) 2 in Group II were sibs with the nephrotic syndrome, and both were male. The biopsies showed pure nephrosis and were positive immunohistochemically. (b) One in Group II was a male with the recurrent haematuria syndrome, who had a family history of kidney disease of unknown nature on the paternal side but no family history of hearing difficulty. The biopsy revealed focal segmental nephritis, and again fluorescence studies were negative.

SEX AND BLOOD GROUP (ABO and Rh). There was no statistical relation between positive fluorescence and either the sex or blood group of the patient.

\section{Discussion}

The method used for this investigation reveals only the presence of human globulin or more specially $\gamma$-globulin in glomeruli, produced by the patient's own immunological organs, i.e. the lymphoreticular tissue.

The demonstrated globulin can be as follows.

(i) Antibody against some glomerular component, that is, auto-antibody.

(ii) Antibody against extrinsic antigenic substance, such as streptococcal antigen in post-streptococcal nephritis or nephrotoxic heteroimmune sera in experimental nephritis.

(iii) Antigen-antibody complex, which was produced elsewhere and unrelated to the glomeruli, such as in serum sickness nephritis.

(iv) Globulin in urine attached to the glomeruli during filtration.

The chi square test revealed the statistical relation $\left(\chi^{2}=5.43,0.01<p<0.025\right)$ between proteinuria and the glomerular-bound globulin. This supports the fourth possibility, the final proof for which is left to the sensitivity of the method and the amount of globulin in the urine.

The demonstration of human complement $C_{1}^{\prime}$ by previous investigators (Burkholder, 1961 ; Lachmann et al., 1962) and by the present author on a limited number of observations indicates that the glomerular-bound globulin is probably of immunological significance, i.e. antibody. However, the true nature of the antibody is still undetermined, since 
the presence of complement can be expected in any of the first three possibilities.

The glomerular-bound globulin demonstrated in this series was not related to streptococci Group A. Therefore, the antigen which provoked the antibody has not yet been identified. A similar investigation was conducted by Seegal (1962) who obtained a positive result in approximately one-third of their cases of acute or chronic nephritis, by treating the renal tissue with antisera against haemolytic streptococci Group A. According to their technique, a positive result indicated the presence of some antigenic component of this organism in glomeruli. However, the same author (1959) could not demonstrate nephrotoxic sera (which is antigen and is considered to be equivalent to the antigenic component of streptococci in post-streptococcal nephritis) in the glomeruli in experimental nephritis of the Masugi type two weeks or so after injection.

The site of localization of the immunohistochemically demonstrated globulin deserves comment. Previous reports have suggested that it lies in the glomerular capillary wall, basement membrane, or mesangium. No conclusions can be drawn from the studies now reported as to the exact site of the bound-globulin other than that the capillary wall is involved, since this has three componentsepithelial and endothelial cells and a basement membrane. In the glomerular stalk the mesangial cells are also possible sites, but these are not clearly differentiated under the fluorescent microscope. A recent electron-microscopic antibody study of experimental nephritis with ferritin-conjugated antisera has localized nephrotoxic sera in the lamina rara of the basement membrane, as well as in epithelial and endothelial cells (Andres, 1962; Arhelger, Gronvall, Carr, and Brunson, 1963).

The results of the present investigation indicate with a fair degree of certainty that some form of immunopathological process is operating in diffuse proliferative glomerulonephritis, in the nephrotic syndrome, in some cases of the recurrent haematuria syndrome, and in the nephritis of the SchönleinHenoch syndrome. In pyelonephritis, the immunopathological mechanism is not clear, but nevertheless the possibility of an immunopathological process cannot be completely ruled out, since suggestive evidence for the glomerular-bound globulin is noted in this investigation. The histological change, including lymphocytic infiltration and lymphofollicular formation, may then well be the manifestation of an immunological process as in homograft rejection. This is generally considered to be a manifestation of infection. Recently Lachmann et al. (1962) have demonstrated a glomerular-bound $\gamma$-globulin in an adult patient with pyelonephritis.

Among the four groups of immunologically determined glomerulopathies, a positive result was most frequently obtained in diffuse proliferative glomerulonephritis, followed closely by the nephrotic syndrome. The other groups were less frequently positive. It must be emphasized that the patients investigated are a highly selected group of children referred to the physicians and surgeons of the hospital, because investigations elsewhere had failed to establish the nature of the renal disorder. The results obtained might well reflect either the strength of the immunopathological process, or the weakness of the immunohomeostatic mechanisms in patients with these forms of glomerulopathy.

It should be emphasized that almost all cases of diffuse glomerulonephritis were positive. Although the significance of circulating antibody is limited, various investigators have reported that positive results were obtained most frequently in the nephrotic syndrome $(90 \%)$, followed by chronic glomerulonephritis $(80 \%)$, and acute glomerulonephritis (70\%) (Lange et al., 1949; Vorlaender, 1957; Liu and McCrory, 1958; McCrory, 1960). When the results with circulating antibody and those with glomerular-bound globulin (antibody) are compared, it may well be considered that the most important role in the pathogenesis of diffuse glomerulonephritis is played by the glomerularbound antibody, while the circulating antibody might be a secondary phenomenon. Simonsen (1953) suggested that local production of antibody might occur in the glomeruli. Furthermore, the case of diffuse glomerulonephritis associated with a- $\gamma$ globulinaemia in this series is of interest, since no circulating antibody, $\gamma \mathrm{G}$, was produced. Gitlin (1962) reported a similar case. If the locally produced antibody is important, the mesangial cell may be the source, especially since this type of cell is morphobiologically similar to the reticulum cell in having phagocytic activity, and thus might have an immunological function (Farquhar and Palade, 1962).

In the nephrotic syndrome, an active immunopathological process is also operating, since results are frequently positive. Especially important from the clinical point of view is the high incidence of positive results in cases undergoing steroid or ACTH treatment $(60 \%)$. More potent steroids or other immuno-depressants are needed for the treatment of the so-called steroid-resistant cases. It should be noted that even five years after the onset there have been two positive cases under treatment in this series. In addition there is no immunohistochemic- 
al evidence of a difference in the steroid resistance in the two types of the nephrotic syndrome, i.e. pure nephrosis and glomerulonephritis with the nephrotic syndrome.

Are pure nephrosis and diffuse proliferative glomerulonephritis immunologically different? This important question cannot be answered by the findings of this investigation. As stated above, however, the nephrotic syndrome shows the highest incidence of circulating anti-kidney antibody, and there is no cellular proliferation or infiltration in the glomeruli in pure nephrosis. It might be speculated on this basis that humoral immunity plays an important role in the immunopathogenesis of pure nephrosis.

The congenital nephrotic syndrome has recently been considered from the immunopathological aspect (Hallman and Hjelt, 1959; Kobayashi, Imahori, and Wakao, 1961; Lange, Wachstein, Wasserman, Alptekin, and Slobody, 1963; Kouvalainen, 1963). It is thought not to be due to an auto-immune process but rather to an iso-immune one, i.e. caused by a maternal antibody produced against foetal kidney. The demonstration of $\gamma \mathrm{G}$ in the case in this series strongly supports the iso-immune hypothesis, since the newborn infant normally produces little or no $\gamma \mathrm{G}$.

In the recurrent haematuria syndrome the cases with purely focal glomerular involvement are significantly less commonly positive $(27 \%)$ than those with diffuse lesions ( $58 \%$ ). The former is the so-called focal nephritis (Ross, 1960; Heptinstall and Joekes, 1961), and probably differs from the latter in immunopathogenesis. Since in the positive cases all glomeruli showed fluorescence, a localized immunopathological process is hardly to be expected. The negative cases may be caused by an entirely different and non-immunological factor, such as a virus. A virus as yet unidentified has been considered to be the causative agent in some cases of glomerulonephritis (Bates, Jennings, and Earle, 1957). The latter could be a type of diffuse proliferative glomerulonephritis. The percentage of positive results in the focal type is fairly constant throughout the clinical course, but that in the generalized type is high within the first year and later becomes low. It is much higher than that of the focal type.

The histopathological findings in the repeated biopsies in the recurrent haematuria syndrome are interesting, since the second biopsy revealed invariably more diffuse glomerular involvement. This indicates that some cases of focal nephritis are progressive, ending as generalized diffuse glomerulonephritis. However, in these cases, the second immunohistochemical results were weak or negative.
In nephritis following the Schönlein-Henoch syndrome there are few positive cases. This might be due to the fact that three steroid-treated cases were included in this group. Alternatively the immunopathological process might differ from that in the other group.

No significant relation between clinical manifestations at the time of biopsy and presence of the glomerular-bound globulin, except proteinuria, was found in the four groups. It should be remembered, however, that none of the cases were subjected to a renal biopsy in the most active phase of the disease. The significant relation between proteinuria and a positive result in these conditions indicates that continuous proteinuria, even of a minor degree, is a sign of the continuity of the immunopathological process in the glomeruli.

Genetic factors are certainly important in various types of immunopathies such as lupus erythematosus, Hashimoto disease, rheumatoid arthritis, and others (McKay and Burnet, 1963; Weldgwood, 1963). In this series, familial incidence, blood types, and sex were considered, but no conclusion can be drawn since the number of cases was small. A positive result is not apparently associated with either the patient's blood group or sex.

Concerning the immunopathogenesis of these renal diseases, no clear-cut explanation is possible at present, except for 'hypersensitivity' in poststreptococcal glomerulonephritis. However, various agents are thought to induce immunological derangement' in the human subject, and this might progress to some form of immunopathological process, causing various types of nephropathy. It is generally accepted that the various types of nephropathy are clinically and pathologically related to each other.

The following points should be considered. Some cases of so-called chronic glomerulonephritis appear rather insidiously without passing through an acute phase. When the patient develops uraemia, renal biopsy may reveal already extensive damage of a chronic nature (Takatsu and Sato, 1962). This is considered to be due to a rather long-standing immunopathological process. In this sense it may well be called 'chronic active glomerulonephritis'. Pure nephrosis also can sometimes be transformed to a glomerulonephritis of a chronic nature (Metcoff, 1962).

Concerning the true nature of this immunological derangement and immunopathological process, various theories and hypotheses have been developed. Among them, those of 'hypersensitivity' or 'auto-immunity' are important for clinicians (Fig. 3). The hypersensitivity theory maintains that glomeru- 


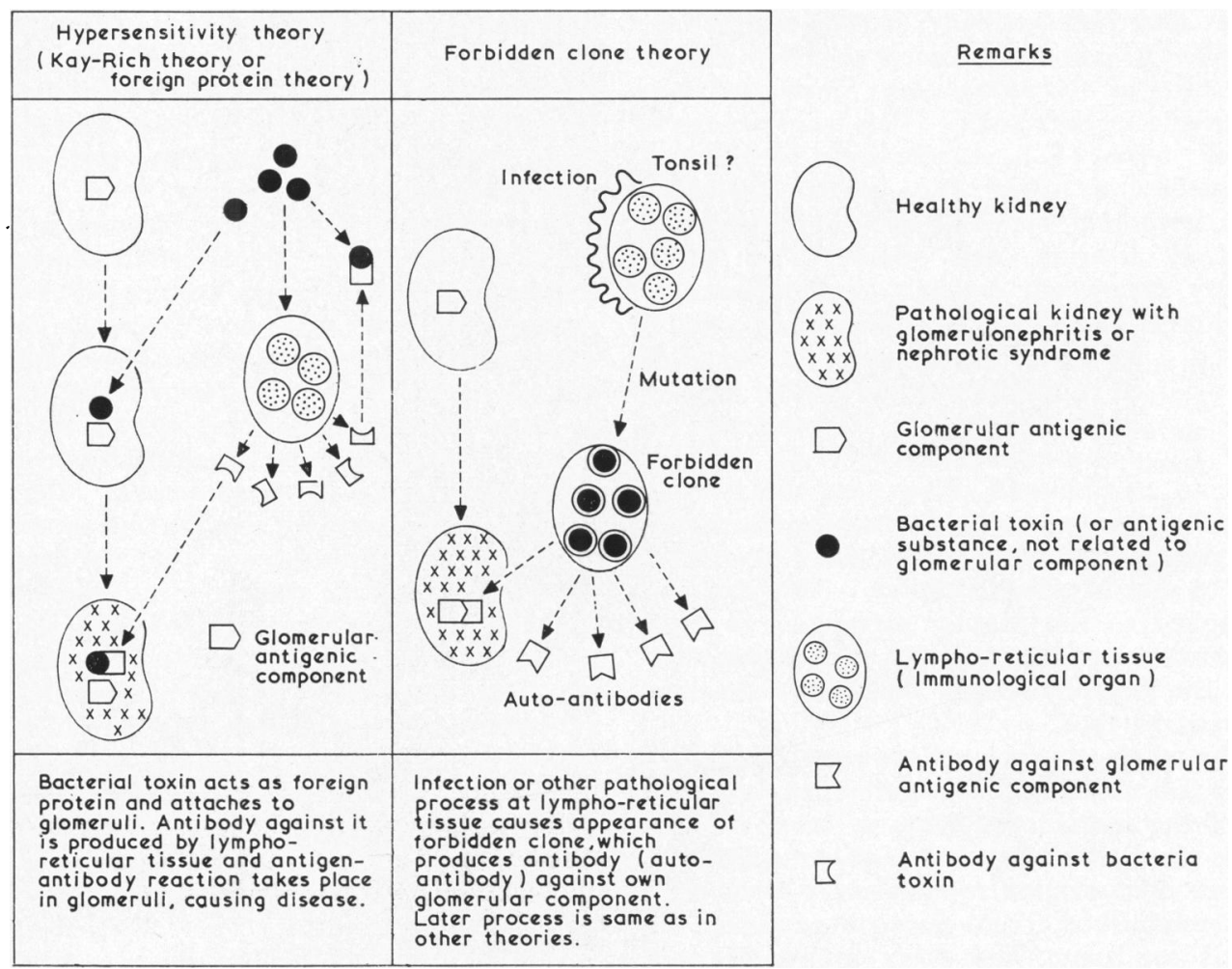

FIG. 2.-Theories on immunopathogenesis of glomerulonephritis and nephrotic syndrome. (References: Kay, 1942; Rich and Gregory, 1943; Sarre and Rother, 1957; Peters and Freedman, 1959; Seegal, 1959; Vernier, Worthen, and Good, 1961; Heymann, 1961; Metcoff, 1962; McKay and Burnet, 1963; Cruickshank, 1963; Humphrey and White, 1963; Rammelkamp, 1962; Rother, 1963; Uhr, 1964; Graber and Miescher, 1964).

lar damage is caused by an antigen-antibody reaction. The antigen, i.e. bacterial toxin in poststreptococcal glomerulonephritis, must become attached to the glomeruli. The auto-immune theory, however, maintains that the patient produces antibody against a component of his own glomerular tissue. Either way, the following two points should be considered.

(i) Antigen should reach the immunological organ, the lympho-reticular tissue, via the body fluid, and blood, i.e. in a soluble form.

(ii) Antigen should be recognized as 'not-self'; otherwise the lymphoreticular system will not make antibody.

Since bacterial toxin is soluble and antigenic, the hypersensitivity theory may explain the development of post-streptococcal glomerulonephritis. However, chronic nephritis and the nephrotic syndrome are not so satisfactorily explained.

The glomerular antigenic component is consider- ed to be insoluble, and it is very unlikely that the glomerular component can reach the lymphoreticular tissue by denaturing or by binding with a haptene.

It has been suggested that a cross-reaction occurs between human kidney and the nephritogenic streptococci (Markowitz, Armstrong, and Kushner, 1960). The cross-reaction between Group A streptococci and cardiac tissue studied by Kaplan (1964) is encouraging in this respect.

The forbidden clone theory proposed by Burnet (1959, 1962) is certainly attractive. Infection or other factors give antigenic stimuli to the lymphoreticular tissue, which causes proliferation and differentiation of the lymphoreticular cells (immunologically competent cells), developing plasma cells and lymphocytes to initiate an immune reaction. During this active proliferation and differentiation, a forbidden clone of immunologically competent cells appears by mutation and they 
produce abnormal antibody, which attacks the glomeruli. In post-streptococcal glomerulonephritis, the site of forbidden clone development is considered to be the tonsils. This theory seems to cover all types of immunologically determined nephropathies, including those of the SchönleinHenoch syndrome, systemic lupus erythematosus, rheumatoid arthritis, and others. The hypersensitivity theory can certainly be considered in association with the forbidden clone theory; that is to say, if the forbidden clone produces an abnormal globulin, which is antigenic to the patient himself, antibody against it is produced. The antibody can react with the abnormal globulin, which has been attached to the glomeruli, or can react with it in the blood to form antigen-antibody complex, which then causes glomerular damage. The latter situation is similar to that in serum sickness. This theory is well applied to the Masugi nephritis. In poststreptococcal glomerulonephritis, the antigen localized to the glomeruli might well be an abnormal globulin of this type.

On the whole, this type of approach, clonal and selective (Burnet, 1959), is important in the future study of the immunopathology of renal diseases. There is much to be done before the true nature of the immunopathological mechanism is established. If it is established, then glomerulonephritis, the nephrotic syndrome, and other immunologically determined renal conditions are auto-immune diseases in the strictest sense.

\section{Summary}

An immunohistochemical study of glomerularbound antibody was carried out on 101 specimens of renal tissue obtained by biopsy or at necropsy, using a modified Coons' fluorescent antibody method. A limited number of specimens was subjected to further studies to demonstrate $\gamma \mathrm{G}, \gamma \mathrm{M}$, complement $\mathrm{C}_{1}^{\prime}$, and streptococcal Group A toxin.

A positive result was always obtained in diffuse proliferative glomerulonephritis and the nephrotic syndrome not under treatment with steroid or ACTH. Approximately $60 \%$ of cases of the nephrotic syndrome under treatment with steroid or ACTH were positive. In the recurrent haematuria syndrome, $65 \%$ of the cases with generalized glomerular involvement were positive, and $35 \%$ of the cases with focal glomerular involvement. Nephritis complicating the Schönlein-Henoch syndrome was less frequently positive, probably because some were treated with steroids. In pyelonephritis the possibility of immunopathological involvement could not be completely ruled out, since some cases gave a doubtful positive result. Miscellaneous renal malformations, metabolic diseases with renal manifestations, and non-renal diseases all gave negative results.

No correlation was noted between a positive result and the major clinical manifestations at the time of biopsy, since biopsy was not performed on a patient with active disease. When the disease is considered to be progressive, an immunopathological process is most likely to be demonstrable, especially in cases showing generalized glomerular involvement. Proteinuria, even of minor degree, is a sign of an active process in the glomeruli. The relation between a positive result and the time of the biopsy after the onset of disease was also considered.

The results of the present investigation support the idea that diffuse proliferative glomerulonephritis, the nephrotic syndrome, some cases of the recurrent haematuria syndrome, especially with generalized glomerular involvement, and nephritis following the Schönlein-Henoch syndrome, are immunologically determined.

Recent ideas on the immunopathogenesis of these diseases are discussed, and the clonal and selective approach of Burnet is emphasized.

The author is indebted to members of the Joint Research Board of The Hospital for Sick Children, Great Ormond Street, and the Institute of Child Health, University of London, for giving him an opportunity to carry out this investigation as a research fellow for three years, and to the physicians and surgeons who gave him permission to study material from their patients. I am indebted to the late Dr. M. Bodian for his encouragement, and I wish to thank Professor Sir Alan Moncrieff, Dr. A. Claireaux, Dr. N. Butler, Dr. J. Barraclough, and Dr. B. Lake for reviewing the manuscript, and Miss R. Jones, Mr. E. Ngaha, and Mr. J. Stiff for their technical assistance.

\section{REFERENCES}

Andres, J. A. (1962). Use of ferritin-conjugated antibody to detect immunologic interaction sites by electronmicroscope. In Hereditary, Developmental, and Immunologic Aspects of Kidney Disease, ed. J. Metcoff, p. 151. Northwestern University Press, Chicago.

Arhelger, R. B., Gronvall, J. A., Carr, O. B., and Brunson, J. G. (1963). Electron microscopic localization of nephrotoxic serum in rabbit glomeruli with ferritin-conjugated antibody. Lab. Invest., 12, 33.

Bates, R. C., Jennings, R. B., and Earle, D. P. (1957). Acute nephritis unrelated to Group A hemolytic streptococcus infection. Amer. F. Med., 23, 510.

Beutner, E. H. (1961). Immunofluorescent staining: the fluorescent antibody method. Bact. Rev., $25,49$.

Black, J. A., and White, R. H. R. (1965). Renal biopsy. In Recent Advances in Paediatrics, ed. D. Gairdner, 3rd ed., p. 307. Churchill, London. 
Bodian, M., Black, J. A., Kobayashi, N., Lake, B. D., and Shuler, S. E. (1965), Recurrent haematuria in childhood. Quart. F. Med., 34, 359.

Bright, R. (1827). Report of Medical Cases Selected with a View of Illustrating the Symptoms and Cure of Diseases by a Reference to Morbid Anatomy, Vol. 1. Longman, London.

Burkholder, P. M. (1961). Complement fixation in diseased tissues. I. Fixation of guinea pig complement in sections of kidney from humans with membranous glomerulonephritis and rats injected with anti-rat kidney serum. f. exp. Med., 114, 605.

Burnet, F. M. (1959). The Clonal Selection Theory of Acquired Immunity. Cambridge University Press, London.

(1962). Autoimmune disease, experimental and clinical. Proc. roy. Soc. Med., 55, 619.

Coons, A. H. (1956). Histochemistry with labeled antibody. Int. Rev. Cytol., 5, 1.

(1958). Fluorescent antibody methods. In General Cytochemical Methods, Vol. 1, ed. J. F. Danielli, p. 399. Academic Press, New York.

Cruickshank, B. (1963). Nephritis, nephrosis, rheumatic fever and myocardial infarction. In Clinical Aspects of Immunology, ed. P. G. H. Gell and R. R. A. Coombs, p. 512. Blackwell, Oxford.

Farquhar, M. G., and Palade, G. E. (1962). Functional evidence for the existence of a third cell type in the renal glomerulus. Phagocytosis of filtration residues by a distinctive 'third' cell. f. Cell Biol., 13, 55.

Freedman, P., Peters, J. H., and Kark, R. M. (1960). Localization of gamma-globulin in the diseased kidney. Arch. intern. Med., $105,524$.

Gitlin, D. (1962). Discussion of Dr. Cood's paper. In The Streptococcus, Rheumatic Fever and Glomerulonephritis. A Symposium held at the New York University School of Medicine, November 27th and 28th, 1962, ed. J. W. Uhr. Williams and Wilkins, Baltimore.

Graber, P., and Miescher, P. A. (1964). (eds.) Mechanisms of immunogenic kidney diseases. In Immunopathology, IIIrd International Symposium, p. 208. Schwabe, Basle.

Hallman, N., and Hjelt, L. (1959). Congenital nephrotic syndrome. f. Pediat., 55, 152.

Heptinstall, R. H., and Joekes, A. M. (1961). Focal glomerulonephritis. In Ciba Foundation Symposium, on Renal Biopsy, ed. G. E. W. Wolstenholme and M. P. Cameron, p. 194. Churchill, London.

Heymann, W. (1961). Pathogenesis of the nephrotic syndrome: consideration based on clinical and experimental studies. f. Pediat., 58, 609.

Humphrey, J. H., and White, R. G. (1963). Hypersensitivity mediated by antibody. In Immunology for Students of Medicine, p. 297. Blackwell, Oxford.

Kaplan, M. H. (1964). Immunologic cross-reaction between Group A streptococcus and mammalian tissue-possible relationship to induction of auto-immunity in rheumatic fever. In The Streptococcus, Rheumatic Fever and Glomerulonephritis, ed. J. W. Uhr, p. 169. Williams \& Wilkins, Baltimore.

Kay, C. F. (1942). The mechanism of form of glomerulonephritis and nephrotic nephritis in rabbits. Amer. F. med. Sci., 204, 483.

Kobayashi, N., Imahori, K., and Wakao, M. (1961). The congenital nephrotic syndrome, a case report and review. Paediat. Univ. Tokyo, 6, 27.

Kouvalainen, K. (1963). Immunological features in the congenital nephrotic syndrome. Ann. Paediat. Fenn., 9, Suppl. 2.

Lachmann, P. J., Müller-Eberhard, H. J., Kunkel, H. G., and Paronetto, F. (1962). The localization of in vivo bound complement in tissue sections. F. exp. Med., 115, 63.

Lange, K., Gold, M. M. A., Weiner, D., and Simon, V. (1949). Autoantibodies in human glomerulonephritis. f. clin. Invest., 28, 50.
—, Wachstein, M., Wasserman, E., Alptekin, F., and Slobody, L. B. (1963). The congenital nephrotic syndrome. Amer. F. Dis. Child., 105, 338.

Liu, C. T., and McCrory, W. W. (1958). Autoantibodies in human glomerulonephritis and nephrotic syndrome. $f$. Immunol., 81, 492.

McCrory, W. W. (1960). Glomerulonephritis in childhood. Mod. Prob. Pädiat., 6, 230.

McKay, I. R., and Burnet, F. M. (1963). Glomerulonephritis. In Auto-immune Diseases, Pathogenesis, Chemistry and Therapy, p. 182. C. C. Thomas, Springfield, Illinois.

—, and Taft, L. I. (1961). Renal biopsy, with particular reference to the study of diabetes mellitus, systemic lupus erythematosus and subacute glomerulonephritis. Aust. Ann. Med., 10, 178.

Markowitz, A. S., Armstrong, S. H., Jr., and Kushner, D. S. (1960). Immunological relationships between the rat glomerulus and nephritogenic streptococci. Nature (Lond.), 187, 1095.

Masugi, M. (1934). UUber die experimentelle Glomerulonephritis durch das spezifische Antinierenserum. Ein Beitrag zur Pathogenese der diffusen Glomerulonephritis. Beitr. path. Anat., 92, 429.

Mellors, R. C., and Ortega, L. G. (1956). Analytical pathology. III. New observations on the pathogenesis of glomerulonephritis, lipid nephrosis, periarteritis nodosa, and secondary amyloidosis in man. Amer. F. Path., 32, 455.

- - - , and Holman, H. R. (1957). Role of gamma globulins in pathogenesis of renal lesions in systemic lupus erythematosus and chronic membranous glomerulonephritis, with an observation on the lupus erythematosus cell reaction. $\mathcal{F} . \exp . \mathrm{Med} ., 106$, 191.

Metcoff, J. (1962). The nephrotic syndrome. In Renal Disease, ed. D. A. K. Black, p. 233 . Blackwell, Oxford.

Nairn, R. C. (1962). Fluorescent Protein Tracing. E. \& S. Livingstone, Edinburgh and London.

Peters, J. H., and Freedman, P. (1959). Immunologic aspects of renal disease. New Engl. F. Med., 261, 1166, 1225, and 1275.

Rammelkamp, C. H. (1962). Aetiology of glomerulonephritis. In Renal Disease, ed. D. A. K. Black, p. 173. Blackwell, Oxford.

Rich, A. R., and Gregory, J. E. (1943). Experimental evidence that lesions with the basic characteristics of rheumatic carditis can result from anaphylactic hypersensitivity. Bull. Fohns Hopk. Hosp., 73, 239.

R̃oss, J. H. (1960). Recurrent focal nephritis. Quart. F. Med., 29, 391.

Rother, K. (1963). Aktuelle Probleme der Autosensibilisierung bei Glomerulonephritis. Int. Arch. Allergy, 22, 306.

Sarre, H., and Rother, K. (1957). Gegen Niere gerichtete Antikörper. A. Die experimentelle Glomerulonephritis. In Immunopathologie in Klinik und Forschung, und das Problem der Autoantikörper, ed. P. Miescher, and K. O. Vorlaender, p. 95. G. Thieme, Stuttgart.

Schick, B. (1907), Die Nachkrankheiten des Scharlach. $\mathscr{f} b$. Kinderheilk., 65, Suppl., 132.

Seegal, B. C. (1959). In vivo localization of specific anti-organ sera : relation to occurrence of renal lesion. In International Symposium, Mechanism of Hypersensitivity, ed. J. H. Shaffer, Gerald A. LoGrippo, and M. W. Chase, p. 143. Churchill, London.

(1962). Fluorescent antibody studies of human glomerulonephritis. In Hereditary, Developmental and Immunologic Aspects of Kidney Disease, ed. J. Metcoff, p. 148. Northwestern University Press, Chicago.

Simonsen, M. (1953). Studies on the pathogenesis of experimental glomerulonephritis. Acta path. microbiol. scand., 32, 85.

Taft, L. I., Dineen, J. K., and McKay, I. R. (1958). The localization and binding of serum proteins in the glomeruli of kidney biopsies in disseminated lupus erythematosus and glomerulonephritis. Aust. Ann. Med., 7, 5. 
Takatsu, T., and Sato, H. (1962). On the specificity of the manifestation of chronic glomerulonephritis in children. Ann. paediat. (Basel), 199, 366.

Uhr, J. W. (1964). (ed.) The Streptococcus, Rheumatic Fever and Glomerulonephritis. A Symposium held at the New York University School of Medicine, November 27th and 28th, 1962. Williams \& Wilkins, Baltimore.

Vazquez, J. J., and Dixon, F. J. (1957). Immunocytochemical study of lesions in rheumatic fever, systemic lupus erythematosus and rheumatoid arthritis. Lab. Invest., 6, 205.
Vernier, R. L., Worthen, H. G., and Good, R. A. (1961). The pathology of the nephrotic syndrome. F. Pediat., 58, 620.

Vorlaender, K. O. (1957). Immunologische Vorgănge bei Nierenerkrankungen. In Immunopathologie in Klinik und Forschung, und das Problem der Autoantikorper, ed. P. Miescher and K. O. Vorlaender, p. 376. G. Thieme, Stuttgart.

Weldgwood, R. J. (1963). (ed.) Symposium on collagen diseases. Pediat. Clin. N. Amer., 10, 855.

Worthen, H. G., Vernier, R. L., and Good, R. A. (1958). The syndrome of infantile nephrosis. Amer. F. Dis. Child., 96, 585. 